\title{
DESIGN SUSTENTÁVEL RADICAL VERSUS MODELO DE MELHORIA INCREMENTAL DOS PRODUTOS: UM OLHAR PANORÂMICO
}

\author{
Lucas Farinelli Pantaleão \\ FAAC/UNESP \\ lucasfarinelli@gmail.com \\ Olympio José Pinheiro \\ FAAC/UNESP \\ holihn@uol.com.br
}

Resumo: O artigo tem como objetivo incitar uma reflexão sobre a substancialidade dos estudos conceituais e práticas projetuais atualmente utilizadas no âmbito do processo de planejamento de produtos sustentáveis. Uma introdução panorâmica acerca de diferentes abordagens de design voltado à sustentabilidade põe como hipótese a distinção perceptiva classificada como "Design Sustentável Radical" e "Modelo de Melhoria Incremental dos Produtos" (Walker). A exploração é uma tentativa de evidenciar uma série de preocupações associadas à cultura material de consumo e a produção pós-industrial globalizada.

Palavras-chave: Design de Produto, Design Sustentável Radical, Modelo de Melhoria Incremental, Cultura Material, Stuart Walker.

\begin{abstract}
With the purpose to provide a brief overview on different approaches of sustainable design, the paper aims to incite a reflection regarding design process in relation to both conceptual and practical studies of product planning. As an evidence of how the sustainable design could be seen today we refer, more precisely, about the perceptual distinction between two different classifications: "Sustainable Radical Design" and "Incremental Improvement Model of Products" (Walker). The paper is an attempt to deal with a number of concerns associated both consumerism material culture as the post-industrial globalized production.
\end{abstract}

Keywords: Product Design, Sustainable Radical Design, Incremental Improvement Product Model, Material Culture, Stuart Walker. 


\section{INTRODUÇÃO}

Pouco mais de um século de design moderno voltado ao industrialismo e à produção em massa acabou por fomentar as convenções particulares da cultura material que é hoje onipresente e considerada normal.

A cultura de consumo material, a qual o design é um dos agentes propulsores, se sustenta através da insatisfação permanente diante do que possuímos e do que desejamos possuir.

A influência sistemática do design process como estratégia de marketing e/ou de valorização distrativa (entretenimento) fomenta um processo constante de inovação e estilização dos bens materiais. Neste sentido pode-se dizer que nosso sistema econômico contemporâneo (capitalismo) vende, mais do que qualquer outra coisa, infelicidade e descontentamento.

Enquanto a produção e o consumo satisfazem os atuais paradigmas econômicos ao se retroalimentarem com crescimento dos negócios através da satisfação do prazer temporário do usuário, mergulha-se na direção de que tal concepção de cultura material torna-se cada vez mais fundamentalmente insustentável, ou mesmo autodestrutiva.

Em consonância com esta linha de raciocínio, felicidade e sustentabilidade, ainda que relativas, sempre irão se traduzir como algo efêmero ou inacessível, a não ser que consigamos romper com este ciclo vicioso.

Como disciplina ativamente envolvida na satisfação das "necessidades humanas" (MASLOW, 1943; HUITT, 2007) acreditamos que o design demanda uma consciência portadora de uma estética, de uma ética e de uma responsabilidade fundamentada em inter-relações morais de valores e significados complexos (objetivos e subjetivos).

De modo a proporcionar um "mapeamento" entre diferentes abordagens do design voltado à sustentabilidade, o artigo pretende incitar uma ponderação frente ao processo projetual de planejamento de produtos no que se refere à estudos de base conceitual e prática projetual.

No intuito de promover uma reflexão ao que comumente é tido como "design de produto sustentável", põe-se como hipótese uma distinção perceptiva entre reconhecidas metodologias aplicadas no âmbito do design de produtos. Trata-se de uma contribuição panorâmica introdutória, inicialmente fundamentada na conceptualização de Stuart Walker ${ }^{1}$ classificada em dois grandes grupos: "Design Sustentável Radical" e "Modelo de Melhoria Incremental dos Produtos" (Walker, 2008).

A exploração é uma tentativa de lidar com uma série de preocupações associadas à atual configuração de cultura material, ao passo que procura evidenciar a substancialidade das diferentes abordagens com as quais o "design sustentável" se apresenta na sociedade de consumo pós-industrial globalizada.

\footnotetext{
${ }^{1}$ Walker, cuja obra compõe o objeto de estudo de nossa pesquisa, é professor e pesquisador de projeto sustentável no laboratório de pesquisa Imagination Lancaster pela University of Lancaster, Reino Unido. Passou grande parte de sua carreira acadêmica no oeste do Canadá, onde foi decano associado da Faculdade de Design Ambiental na Universidade de Calgary. Sua pesquisa tem como foco a estética do design de produtos sustentáveis e seus trabalhos concentram-se na "estética sustentável" do produto e sua re-significação. Desenvolve um "design proposicional" que tem sido exibido em apresentações exclusivas no Design Museum em Londres, Canadá e Europa.
} 
Com esta referência procuramos contribuir para a criação e reflexão do planejamento de produtos, nos quais se articulem uma nova concepção de projeto, onde diferentes metodologias de design procuram alternativas capazes de subverter a atual cultura de consumo, a fim de se sintonizar com os novos paradigmas sistêmicos, holísticos e ecológicos, no contexto da sociedade pós-industrial contemporânea.

\section{DESENVOLVIMENTO}

Além de representar uma crise ambiental, econômica e social, o problema da sustentabilidade nos leva a questionar muitas de nossas suposições mais básicas no sentido de reexaminarmos a necessidade de alterar especialmente as abordagens mais conformistas.

Pode-se dizer que um dos grandes desafios do design contemporâneo reside em abordar questões sustentáveis de uma forma muito mais substancial do que tem sido evidente até agora. Para que os designers possam enfrentar o desafio do desenvolvimento sustável de modo mais efetivo (significativo) faz-se necessário reavaliar, de maneira mais desafiadora, alguns dos pressupostos fundamentais do próprio design de produto.

$\mathrm{Na}$ edição inaugural do IJSDes (International Journal of Sustainable Design), 2008, Stuart Walker propõe uma distinção polêmica, contudo digna de consideração, acerca de como o design de produto voltado à preocupações de sustentabilidade é visto atualmente.

Walker propõe uma distinção entre reconhecidas abordagens "sustentáveis" de design classificadas em dois grandes grupos: "Design Sustentável Radical" e "Modelo de Melhoria Incremental do Produto". O autor, apesar de reconhecer que ambas abordagens estão interligadas, esclarece que a última está intimamente associada à compreensão mais difundida do que comumente é tido como "design de produto sustentável" (WALKER, 2008).

Walker defende que o design contemporâneo é potencialmente capaz de desenvolver novas habilidades criativas vitais para um mundo onde o consumo excessivo e o desperdício vem agravando os efeitos destrutivos sobre o ambiente natural. No entanto, adverte que devemos estar preparados para ampliar nossos horizontes e passarmos a ver os designers não apenas como meros criadores de novos produtos, mas como criativos que pensam e contribuem para a natureza, concepção e significado cultural da humanidade (Idem, op. cit., p. 6).

Segundo o autor, os designers deverão desempenhar um papel importante na re-conceptualização e re-definição de nossas noções mais básicas dos objetos cotidianos. Todavia, para que isso venha a acontecer, Walker afirma que o design deve extrapolar as noções muitas vezes rasas do planejamento de produto baseado em questões de estilo que se tornaram comuns ao longo dos últimos 50 anos (Idem op. cit., p. 4). Conforme sustenta: "if designers are to address the challenge of sustainability in a more substantive manner, they must question the ways in which they design, the assumptions they make, and the products of design" 2 (Idem op. cit., p. 6).

\footnotetext{
2 "Se os designers pretendem enfrentar o desafio da sustentabilidade de maneira mais substancial, eles devem questionar as formas como projetam, os pressupostos que partem e o próprio design de produto" (Tradução nossa).
} 
A partir deste contexto Walker elenca uma série de estratégias de design desenvolvidas no últimos anos voltadas a melhorar o desempenho ambiental e, em alguns casos, as ramificações sociais associadas à produção atual.

$\mathrm{Na}$ condição de "Modelos de Melhoria Incremental" dos produtos, Walker elenca programas como The Natural Step (ROBERT, 2002), Cradle-to-Cradle Design (MCDONOUGH e BRAUNGART, 2002; 2014), Product Life Cycle Assessment (GUINÉE, 2002) e Factor 10 (SCHIMIDT-BLEEK, 2008).

Em contraponto às abordagens acima mencionadas, para ele tidas como "elementares", Walker elenca uma série de outras estratégias, tanto teóricas como práticas, que considera essenciais para enfrentar os desafios impostos pela atual cultura material de consumo. Por conceituá-las como sendo abordagens mais exigentes, difíceis de prever e menos confortáveis, o propositor as define como "Design Sustentável Radical", uma vez que acredita serem capazes de desafiar as convenções contemporâneas e os pressupostos mais básicos no que diz respeito à natureza criativa dos produtos (Idem op. cit., p. 5).

De acordo com Walker, dentre as abordagens radicais estão: a psicologia do consumismo e suas formas mais significativas de criação de "objetos emocionalmente duradouros" (CHAPMAN, 2005), a noção ativista de "slow-design" que incide sobre o bem-estar pessoal, sócio-cultural e ambiental ao contrariar a noção de projeto com foco no objeto (FUAD-LUKE, 2009), além das inúmeras "soluções possíveis" catalogadas por Manzini \& Jégou (2003a e 2003b) que visam um maior envolvimento dos usuários na criação e desenvolvimento de seus próprios produtos e serviços (WALKER, 2008, p. 7-8).

No sentido de incitar uma reflexão sobre o processo projetual de planejamento de produtos frente às diferentes abordagens mencionadas, discorreremos brevemente sobre cada uma delas e seus respectivos autores/fundadores a seguir. Na sequência incluímos uma breve introdução à abordagem particular de Stuart Walker ("Projetando Sustentabilidade") acompanhada por um diagrama que procura sintetizar a visão do autor.

\subsection{Modelo de Melhoria Incremental do Produto}

Proposta no início dos anos 1990 em parceria com um grupo de mais de cinquenta cientistas, a metodologia atualmente conhecida como The Natural Step (TNS) é atribuída ao oncologista sueco Dr. Karl-Henrik Robèrt. Por se tratar de uma abordagem abrangente com vistas à sustentabilidade o TNS é comumente adotado por muitos designers.

Focalizando uma conciliação sustentável frente à novas práticas e modelos de negócio, estratégias e processos organizacionais, produtos e inovação de serviços, o TNS consiste basicamente em estabelecer uma projeção desejada para o futuro e traçar o planejamento estratégico cabível para atingi-la. Na tentativa de estabelecer uma compreensão basilar do que torna a vida possível de maneira complexa, a base do TNS se fundamenta no pensamento sistêmico direcionado pelas leis da termodinâmica, estudos sociais e ciclos naturais.

Na prática, tem seu alicerce fundado sobre quatro princípios: 1) formação de líderes para a sustentabilidade; 2) medição do desempenho das práticas atuais; 3) estabelecimento de valores duráveis e 4) o aprendizado com o futuro. Na qualidade de 
organização sem fins lucrativos possui atualmente escritórios de consultoria em 11 países e numerosos colaboradores em todo mundo, incluindo o Brasil.

O termo Cradle-to-Cradle ("do berço ao berço") foi cunhado pelo arquiteto suíço Walter R. Stahel na década de 1970 . Originalmente fundado com vistas às competências de ordem projetuais (arquitetura, engenharia, design etc.), é caracterizado por uma abordagem que focaliza o entendimento de que a indústria e a tecnologia devem proteger e enriquecer os ecossistemas através do metabolismo biológico da natureza ao evitar o desperdício de matéria e energia.

Sob a forma de manifesto que dá detalhes específicos acerca de como alcançar o modelo, o químico alemão Michael Braungart e o arquiteto norte-americano William McDonough publicaram em 2002 o livro Cradle to Cradle - Remaking the Way We Make Things, (New York, North Point Press). O texto teve sua edição ampliada e traduzida para o português como "Cradle to cradle - criar e reciclar ilimitadamente" (São Paulo, GGBrasil), 2014.

A proposta fundamental do cradle to cradle é questionar o conceito superficial de ecoeficiência no intuito de mostrar que, a longo prazo, seus efeitos serão da mesma forma destrutivos. Ao admitir que vivemos em um sistema fechado (o planeta Terra), regido basicamente por dois elementos essenciais, massa (a Terra) e energia (o Sol), nada entra e nada sai deste sistema exceto calor ou algum meteorito ocasional.

Ao lançarem o mote: "a forma segue a evolução", os autores defendem a ideia de que, se continuarmos a contaminar a massa biológica da terra e desperdiçar materiais técnicos como os metais, por exemplo, acabaremos em um mundo limitado, no qual a produção e o consumo serão reprimidos. Nesta direção, caso isso eventualmente viesse a acontecer o planeta Terra passaria de berço ("cradle") para cova ("grave") (MCDONOUGH; BRAUNGART, 2014, p. 106-7).

Sobre essa ideia central que caracteriza o princípio norteador do cradle to cradle, transcrevemos alguns apontamentos dos autores, inicialmente na forma de indagação supositiva:

O que teria acontecido, às vezes nos perguntamos, se a Revolução Industrial tivesse ocorrido em sociedades que enfatizassem a comunidade em vez do indivíduo e nas quais as pessoas não acreditassem em um ciclo de vida cradle to grave, mas na reencarnação? (Idem ibidem).

A partir de tal suposição, passam a especular:

Se nós, os seres humanos, realmente quisermos prosperar, então teremos de aprender a imitar o Sistema natural cradle to cradle, altamente eficaz, de fluxo de nutrientes e de metabolismo, no qual o próprio conceito de desperdício não existe. [...] Isso significa que os nutrientes valiosos contidos nos materiais moldam e determinam o projeto: a forma segue a evolução, não apenas a função. Pensamos que essa é uma perspectiva mais robusta que o modo atual de fazer as coisas (Idem ibidem).

O Product Life Cycle Assessment (Product LCA - análise ou avaliação do ciclo de vida dos produtos) se refere à um conceito bastante comum no universo do atual design tido como "sustentável". Corresponde sumariamente a um conjunto sistemático de procedimentos de quantificação e classificação com a finalidade de examinar as entradas e saídas de materiais e de energia e os impactos ambientais atribuíveis ao funcionamento de um dado sistema de produto ou serviço ao longo do seu ciclo de vida. Suas análises são reguladas pelas normas internacionais da série ISO 
(International Organization for Standardization) 14040 e compreende princípios de estrutura, gestão ambiental, avaliação do ciclo de vida, requisitos e orientações sugestivas (GUINÉE, 2002, p. 5-6).

A "Teoria do Fator 10", assim como o "Natural Step" (TNS), não corresponde à uma proposição nativa da área do design. Atualizada no início da década de 1990 pelo químico e pesquisador ambiental alemão Friedrich Schmidt-Bleek como uma projeção da menos drástica "teoria do fator 4", consiste na ideia de que a humanidade precisa reduzir a rotatividade de recursos em $90 \%$; em escala global e dentro dos próximos 30 a 50 anos.

A meta final do Fator 10 é assegurar que as nações não excedam a capacidade de transmitir recursos suficientes para as gerações futuras. Fundamentada no conceito de "desmaterialização", amplamente abordado por Schimidt-Bleek, defende que é imprescindível reduzir o uso de energia à medida em que se promova o aumento da eficiência e da produtividade dos recursos: ambos por um fator de 10. Neste sentido, segundo o propositor, a fim de garantir a sustentabilidade e a preservação do meio ambiente seria preciso reverter o processo de produção e consumo em $90 \%$ (SCHIMIDT-BLEEK, 2008, p. 1-4).

Tais abordagens, quando vistas de uma perspectiva estritamente técnica em relação às metodologias e processos de design no âmbito da concepção de produtos sustentáveis caracterizam, na denominação de Walker, apenas "Modelos de Melhoria Incremental" dos produtos. Para o autor, tais abordagens não são capazes de atenuar certos efeitos negativos característicos da cultura material. Logo, não solucionam o problema de maneira significativa (WALKER, 2008, p. 5).

Conforme salienta o autor:

All of these offer pragmatic solutions for modifying current practices in order to reduce the negative impacts of product design and production. They are important models for implementing improvements in the existing system, but they do little to challenge the basis of that system. [...]These approaches can be seen, in varying degrees, as part of the problem rather than the solution because they bolster, rather than challenge, the current consumerist model of a totally commodified material culture - a model that is manifestly destructive ${ }^{3}$ (Idem ibidem).

\subsection{Design Sustentável Radical}

Formulado por Jonathan Chapman", o termo "design emocionalmente duradouro" tem sido amplamente adotado por teóricos da área como uma espécie de

\footnotetext{
3 "Todas estas abordagens oferecem soluções pragmáticas para modificar as práticas atuais a fim de reduzir os impactos negativos do projeto de produto e produção. São modelos importantes para a implementação de melhorias no sistema existente, mas pouco fazem para desafiar a base desse sistema. [...] Essas abordagens podem ser vistas, em diferentes graus, como parte do problema e não a solução, pois reforçam, ao invés de desafiar, o modelo atual consumista de uma cultura material totalmente mercantilizada - um modelo que é manifestadamente destrutivo" (Tradução nossa).

4 Jonathan Chapman é professor de Design pela Universidade de Brighton, Reino Unido. Seu trabalho tem sido aclamado pela mídia, incluindo New York Times, The Guardian, The Independent, e BBC. A revista New Scientist o descreveu como "motor agitador" de uma "nova geração de pensadores do design sustentável'. Em 2008 foi convidado pela House of Lords a fim de apresentar provas formais como parte de seu Inquérito sobre redução de resíduos e assessoria na elaboração de políticas ambientais da União Europeia para a concepção e descarte de produtos eletrônicos. É membro de vários conselhos consultivos de sustentabilidade, incluindo Puma, D\&AD e Museu do Design (http://arts.brighton.ac.uk/staff/jonathan-chapman).
} 
"atalho" para descrever os múltiplos e complexos fatores que determinam o valor e o significado de um determinado objeto, espaço ou experiência. Em seu livro Emotionally Durable Design. Objects, Experience, Empathy (London: Earthscan), 2005, Chapman descreve como o processo de consumo é, e sempre foi, motivado por direcionamentos emocionais complexos que vão muito além da simples compra, sem sentido, de coisas mais recentes ou esteticamente mais bem vistas (CHAPMAN, 2005).

Com o foco na redução do consumo e do desperdício de recursos naturais, a abordagem visa estender o tempo e ampliar a capacidade de resiliência das relações estabelecidas entre os produtos (objetos/artefatos) e os usuários ("consumidores"). Edificada em estudos sobre a psicologia do consumismo, focaliza seus esforços na busca da auto afirmação através do desejado. Ao admitir que o consumismo é constantemente retroalimentado por ciclos conjunturais de desejo e decepção, procura alternativas capazes de romper com a atual cultura material predominante no sistema capitalista da sociedade pós-industrial (Idem ibidem).

Em nota introdutória vejamos como Chapman discorre sobre sua abordagem:

Emotionally Durable Design reframes the environmental paradigm, increasing resource productivity and reducing waste by elongating the lifespan of products. [...] it espouses the emergence of a specialist design genre that caters for deeper, more profound and poetic human needs, taking users beyond the ephemeral world of technocentric design toward a rich, interactive domain of emotionally durable objects and experiences. [...] Emotionally Durable Design is an exploration into product lifetimes; belonging to the growing knowledge field of sustainable design ${ }^{5}$ (Idem, op. cit., p. 24-5).

Com origem no conceito slow-food cunhado em contraste à noção de fast-food, o que hoje é conhecido como "slow-design" corresponde à apropriação do movimento 'slow' no âmbito do design. Assim como acontece com todos os segmentos do movimento 'slow', o slow-design se caracteriza como uma abordagem que incentiva um processo mais lento, ponderado e reflexivo.

A primeira publicação oficial, considerada como o "manifesto do slow-design" é atribuída à Alistair Fuad-Luke ${ }^{6}$ através do artigo intitulado: SlowDesign - a paradigm for living sustainably, 2003. Na ocasião, ao apartar o design das considerações de ordem econômicas, Fuad-Luke chamava a atenção para um reposicionamento do foco do design inscrito na tríade: bem-estar individual, sociocultural e ambiental ${ }^{7}$. Com o

\footnotetext{
5 “O Design emocionalmente duradouro reformula o paradigma ambiental, aumentando a produtividade dos recursos e reduzindo o desperdício prolongando a vida útil dos produtos. [...] isso reforça o surgimento de um gênero de design específico que atenda necessidades humanas mais profundas e poéticas, levando os usuários para além do mundo efêmero do desenho tecnocêntrico, em direção a um rico domínio interativo junto a objetos emocionalmente duráveis e experienciais. [...] Design emocionalmente duradouro é uma exploração intrínseca sobre o tempo de vida do produto; que atravessa o campo de conhecimento crescente do design sustentável" (Tradução nossa).

${ }^{6}$ Alastair Fuad-Luke se auto intitula facilitador do design sustentável, educador, escritor e ativista. Autor de livros como: Design Activism: Beautiful Strangeness for a Sustainable World, Oxon: Earthscan, 2009 e The Eco-Design Handbook: a Complete Sourcebook for the Home and Office, London: Thames \& Hudson, 2009, é considerado fundador do movimento slow-design. Atualmente é professor visitante na University of Plymouth, University College for the Creative Arts, University College Falmouth, e na Royal College of Arts, no Reino Unido (http://www.fuad-luke.com).

${ }^{7}$ No início do século XXI a sustentabilidade era amplamente discutida em termos triádicos. O TBL ou 3BL ("Triple-Bottom Line") que propunha a integração entre das esferas, social, ambiental e econômica ("People, Planet \& Profit; or Prosperity") foi consagrado como o mantra da época. Responsável por
} 
passar dos anos algumas vertentes vem procurando uma forma de conciliar esta visão sem deixar de lado a esfera econômica ${ }^{8}$.

$\mathrm{Na}$ esteira "contracultural"9 adotada como metodologia alternativa pelo design, a abordagem 'slow' procura se firmar em oposição à velocidade vertiginosa do atual paradigma pós-industrial. Mais precisamente ao que poderíamos entender como "fast-design". Este, constantemente estimulado por uma "ética" de mercado que define todo ser humano como um cliente em potencial, prioriza uma sucessão de ciclos insustentáveis baseados em tendências efêmeras e no consumo excessivo. 0 conceito de "fast-fashion" pode ser tido como um exemplo de "fast-design".

O emprego do termo "slow" na condição de adjetivo visa deliberadamente incitar uma ambiguidade. Ao pressupor que o tempo está implícito em todas as facetas do processo de design, a lógica da lentidão tem como meta retardar tanto o planejamento e a concepção de novos (e mais) produtos, como também seus resultados e efeitos consequentes (ERLHOFF, MARSHALL, 2008, p. 361).

Nesta direção Fuad-Luke postulou oito princípios que, sobrepostos, regem a noção central do conceito de slow-design. São eles: 1) ritual; 2) tradição; 3) experiência; 4) evolução; 5) lentidão; 6) eco-eficiência; 7) conhecimento de código aberto e 8) slow-tecnologia (Idem, op. cit., p. 362).

Vejamos como Fuad-Luke e Carolyn F. Strauss, ambos fundadores do New York's SlowLab (http://www.slowlab.net/) definem a noção de slow-design em termos de ativismo criativo:

cunhar o termo, John Elkington ficou mundialmente conhecido como autoridade em responsabilidade corporativa e desenvolvimento sustentável. Sua primeira aparição remonta à infância, quando aos 11 anos arrecadou dinheiro para a recém-formada World Wildlife Fund (WWF). Em 2008, o Evening Standard o classificou entre as "1000 pessoas mais influentes" do mundo descrevendo-o como "um verdadeiro guru do negócio verde" (JOHN ELKINGTON In. WIKIPÉDIA, 2015).

${ }^{8} \mathrm{O}$ aumento do uso da terminologia TBL expôs lacunas comprovadamente incapazes de explicar todas as atividades humanas. Hoje o debate da sustentabilidade gira em termos de Quadruple Bottom Line (QBL). Ainda sem consenso sobre qual princípio este deveria encerrar duas concepções vem ganhando espaço nesta corrida terminológica segundo a Social Enterprise Associates: são os conceitos de "cultura" e de "espiritualidade". A título de introdução pontual podemos citar a abordagem de Fleming e Sherman que descrevem detalhadamente o QBL como uma ferramenta capaz de mensurar e aprimorar uma pedagogia do design para a sustentabilidade, a partir da inclusão de fatores como experiência humana e desenvolvimento consciencial. Para um panorama aprofundado neste sentido veja: WALKER, 2014; FLEMING, 2013; INAYATULLAH, 2009.

9 A "contracultura" designa um conjunto de manifestações artísticas, existenciais e culturais, características da revolta contra as instituições, os valores, os hábitos, as hierarquias e as tradições dominantes da sociedade ocidental. Um dos primeiros movimentos da contracultura surgiu nos EUA na década 1950 com a chamada Beat Generation, jovens intelectuais, em sua essência artistas e escritores, que contestavam o consumismo e o otimismo do pós-guerra americano. Os Beatniks, como ficaram conhecidos, procuravam subscrever o estilo de vida anti-materialista, o anticomunismo generalizado e a falta de pensamento crítico. Posteriormente, já na década de 1960, o mundo conheceu o principal e mais influente movimento de contracultura já existente, o movimento Hippie. Os hippies se opunham radicalmente aos valores culturais dominantes, entre eles o trabalho, o patriotismo e nacionalismo, a ascensão social e até mesmo a "estética padrão", caracterizada pela estética moderna também conhecida com Estilo Internacional. No design, esse mesmo espírito de revolta dá lugar a experiências heterodoxas e a grupos que passam a ser denominados como Antidesign. São exemplos o Archigram e Archizoom, cuja filosofia propõe uma revalorização da função estética do objeto, vinculada a valores pluralistas e ao resgate pré-modernista. O que mais tarde vai influenciar o design pós-moderno italiano, como nas obras de Ettore Sottsass por exemplo. (CONTRACULTURA. In: WIKIPÉDIA, 2015; CARDOSO, 2008, p. 199-200; PANTALEÃO, L. F.; PINHEIRO, O. J, 2008). 
A way of thinking, designing, making and doing that focuses on, and beyond, the materialized artifact or environment in order to raise fresh perspectives, encourage reflection, challenge intentions, and deepen life's experiences ${ }^{10}$ (Idem ibidem).

Ainda embasados na classificação de Stuart Walker outra abordagem pertinente à categoria de Design Sustentável Radical consiste na farta quantidade de "soluções possíveis" registradas por Ézio Manzini ${ }^{11}$ e Francois Jégou ${ }^{12}$ nas edições Sustainable Everyday: scenarios of urban life, e Album: a catalogue of promising solutions, ambas publicadas em 2003 pela Edizione Ambiente de Milão.

Tais referências correspondem à 72 soluções catalogadas em países como Brasil, Canada, China, Coreia, Finlândia, França, Japão, Índia, Itália e USA, que refletem o resultado de um programa internacional de pesquisa que procurou levantar formas diferentes, porém possíveis de se viver.

Ao traçar um cenário detalhado de diferentes alternativas sustentáveis de viver a vida, faz especial referência ao ambiente urbano e ao futuro dos estilos de vida domésticos. Os exemplos procuram fornecer subsídios para que leitor formule sua própria opinião e faça escolhas individuais, porém com um nível de informação dilatada.

$\mathrm{Na}$ abordagem o foco não incide sobre como a tecnologia é capaz de remodelar funções tradicionais, mas em "estratégias de vida" emergentes que estão se tornando possíveis e, pelo menos para alguns, desejáveis nos dias de hoje. Através de possibilidades reais e alternativas viáveis, o "Diário Sustentável" procura criar uma imagem do estado-da-arte acerca de como estamos respondendo de forma criativa às dificuldades da vida cotidiana atual. Diferentes e peculiares formas de viver emergem principalmente da inovação social e sistêmica do que do desenvolvimento tecnológico.

Nas palavras de Manzini e Jégou:

Sustainable Everyday is an initiative that accepts the risk of making suggestions and consequently of seeming naïve. That said, we do not wish to seem, and are not being, unrealistic - the steps towards the sustainable city that we put forward here are undoubtedly difficult (how could they not be, given the complexity of the problems we must collectively face), but they are practicable. [...] The capacity to imagine something that does not exist and the strategy for archieving it is the essence of every forward looking attitude towards reality. Assuming this attitude and putting it into practice is neither obvious nor simple. [...] Indeed, it would

\footnotetext{
10 “Uma forma de pensar, projetar, produzir e fazer que incide sobre, e para além, da materialização do artefato ou do ambiente, com intuito de edificar novas perspectivas, incentivar a reflexão, desafiar intenções e aprofundar as experiências de vida" (Tradução nossa).

${ }^{11}$ Ezio Manzini é professor de Design no Politécnico de Milão, onde é diretor da unidade de pesquisa Design e Inovação para a Sustentabilidade. Coordena o mestrado em design estratégico e o doutorado em programas de design industrial. Atua na vertente do design estratégico e design para a sustentabilidade, com foco na criação de cenários e desenvolvimento de soluções. Atualmente é professor visitante e consultor em universidades na China, Japão, Austrália, Holanda e Brasil (UFRJ). Possui livros traduzidos em diversas línguas (http://www.sustainable-everyday-project.net/people).

12 François Jégou é consultor de design estratégico com licenciatura em design industrial. Atua como professor visitante no Politécnico de Milão e na La Cambre School, em Bruxelas. Dirige a consultoria SDS (Students for a Democratic Society), com especialização em definição de cenários em eco-design e novos sistemas de produtos-serviços, design sustentável, design de interação, ergonomia cognitiva, design sênior amigável e inovação em produtos alimentares. A SDS é ativa em vários projetos de investigação da União Europeia (http://www.sustainable-everyday-project.net/people).
} 
appear to be the only social resource indispensable to activating any noncatastrophic transition towards sustainability ${ }^{13}$ (MANZINI, JÉGOU, 2003a, p. 1319).

É importante salientar que as diferentes abordagens reproduzidas aqui, consoante às observações de Stuart Walker, refletem apenas um breve recorte de alguns dos principais instrumentos metodológicos atualmente relacionados à atividade do design com vistas à sustentabilidade. No que tange ao Design Sustentável Radical, um panorama mais completo pode ser encontrado de forma sistematizada no volumoso compêndio organizado por Walker e Jacques Giard intitulado: The Handbook of Design for Sustainability (Londres: Bloomsbury Academic), 2013.

O compêndio que reúne mais de 40 colaboradores de vários cantos do mundo pode ser considerado o estado-da-arte no que se refere à bibliografia atual do design para sustentabilidade. Divido em quatro partes, sintetiza: 1) o design sustentável das perspectivas históricas e teóricas; 2) as metodologias e abordagens conceituais; 3) o design sustentável na prática e 4) sugestões inovadoras e diretrizes para o futuro da sustentabilidade no design.

\section{3 "Projetando Sustentabilidade": design acadêmico "proposicional", de abordagem radical. A "Forma Segue o Significado" em Stuart Walker}

O foco principal da abordagem de design particular proposta por Walker se volta à redefinição dos objetos funcionais através da inclusão de valores substanciais imbuídos de significado humano (WALKER, 2014).

Ao propor um distanciamento temporário entre a academia/universidade e as considerações de ordem econômicas, o autor visiona um olhar radical sobre o ato fundamental de "pensar-e-fazer" design ("think-and-doing").

Por meio de explorações experimentais, as quais prefere denominar "design proposicional" ("propositional design"), Walker evidencia o design como uma disciplina que depende da imersão íntima. Para ele, "por mais eloquentes que possam parecer os postulados teóricos, sem a concretização prática não existiria design" (WALKER, 2014, p. 1-3 - Tradução nossa). Neste sentido, Walker desenvolve uma espécie de metodologia em espiral do design, de certo modo regida pelo próprio processo criativo do designer (autoconsciente), durante todo o ato fundamental de "projetar sustentabilidade" ("Designing Sustainability").

$\mathrm{O}$ autor acredita que o design pode ser visto como um ingrediente essencial para uma abordagem de pesquisa mais holística que combina a "análise racional (conhecimento cognitivo e interpretação) com a tomada de decisão intuitiva (conhecimento tácito e expressão), ambos moderados pela teoria e por princípios gerais distintos na síntese específica de cada projeto" (WALKER et. al. 2013, p. 451 Tradução nossa). Para Walker, "pesquisa em design", ao contrário de como pode ser

\footnotetext{
13 “Diário Sustentável é uma iniciativa que aceita o risco de tecer sugestões e, consequentemente, de parecer ingênuas. Dito isso, não queremos parecer, e não somos, irrealistas - os passos para a cidade sustentável que apresentamos aqui [no livro] são, sem dúvida difíceis (como eles poderiam não ser, dada a complexidade dos problemas que temos de enfrentar coletivamente), mas praticáveis. [...] A capacidade de imaginar algo que não existe e a estratégia para alcançá-la é a essência de cada atitude prospectiva em direção a realidade. Assumir esta atitude e colocá-la em prática não é uma tarefa simples, muito menos óbvia. [...] Na verdade, parece ser o único recurso social indispensável para ativar qualquer transição não catastrófica em direção à sustentabilidade" (Tradução nossa).
} 
entendida no meio acadêmico ("scholarly research"), se refere ao processo de design que inclui a prática como um modo de exploração, expressão e aprendizado (Idem op. cit., p. 447) ${ }^{14}$.

Em oposição tanto ao princípio modernista - para ele, "precoce" - "a forma segue a função" bem como seu contraponto pós-moderno "less is a bore" que prioriza explorações inconsequentes e variações da moda pouco preocupadas com suas próprias consequências (WALKER, 2011, p. 3-4), Walker resume seu trabalho com o mote "form follows meaning" ("a forma segue o significado").

Ao defender que noções mais profundas de significado humano, como desenvolvimento interior e bem-estar espiritual são vitais para uma compreensão mais abrangente da sustentabilidade (WALKER, 2006; 2011; 2014), sua abordagem peculiar toma como premissa a relação bilateral entre o material e o subjetivo (função prática / função estética-função simbólica). Nesta direção, o design teorizado e praticado por Stuart Walker focaliza a pretensão de atingir os mesmos graus de perenidade atribuída à artefatos culturais singulares, historicamente encontrados em tradições espirituais milenares (ocidentais e orientais).

\section{CONSIDERAÇÕES FINAIS}

O debate acerca do design norteado pela sustentabilidade envolve princípios fundamentais, filosofias e metodologias de trabalho que perpassam os limites estritamente disciplinares. Em um mundo onde optar por uma atuação mais consciente e responsável significa contestar as pressões do consumismo, do desperdício e da preocupante crise ecológica, ao nos colocarmos em contato com experiências distintas da área, novos insights podem surgir no sentido de promover uma compreensão mais abrangente.

Teoria do design, prática do design e sustentabilidade, uma vez unidas por interligações sistêmicas complexas, permeiam todas as instâncias do projeto. Das intenções e decisões pragmáticas, passando pelos critérios e preferências estéticas até às noções de valores e significado, o design contemporâneo abrange um contexto cultural extremamente amplo.

Cientes da responsabilidade do design, cuja diversidade de abordagens relativas à sustentabilidade partilham, agora mais do que nunca, de imposições ecossistêmicas complexas imprescindíveis para a construção de um futuro melhor, acreditamos em reflexões e experimentações que desafiam a condicionalidade do projeto incremental com vistas à uma percepção mais holística e transdisciplinar do design.

Partilhamos da opinião de Walker que um caminho menos consumista, e por consequência, mais sustentável, exige uma laboriosa transmutação estrutural nas bases do sistema que rege a atual cultura material capitalista. Neste contexto, o design não só pode como deve prestar sua contribuição no sentido de promover uma compreensão mais profunda da Real-idade, através da re-valorização humanitária.

A dificuldade em alavancar uma transformação substancial parece residir justamente na manutenção das expressões convencionais. A preocupação constante em atender a prioridade da ordem econômica eclipsa o processo de planejamento

\footnotetext{
${ }^{14}$ Visão esta que talvez poderíamos traduzir como uma distinção entre "pesquisa aplicada em design" e "pesquisa fundamental em design".
} 
contemporizado, capaz de zelar por caracteres subjetivos (emocionais e intelectuais) intrínsecos às abordagens mais eco-lógicas.

No que tange à relação 'processo-produto-usuário', o design se destaca como agente promotor de uma conscientização voltada para um novo modo de vida em suas múltiplas e complexas relações com a atual cultura material da sociedade de consumo pós-industrial globalizada. Logo, faz-se necessário olhar não apenas para a satisfação das necessidades materiais dos indivíduos isoladamente, mas é preciso abarcar também as esferas 'imateriais' do social, cultural, ambiental e humano. Neste contexto cabe ao design e aos designers projetar não fragmentariamente, mas, ao contrário, levar em conta esse conjunto sistêmico de atributos como um todo.

Com o objetivo de destacar a particular distinção acerca do que Walker considera fundamental e complementar entre as abordagens citadas ao longo deste artigo, elaboramos o diagrama abaixo de modo a prestar uma contribuição visual de síntese (Fig. 01 - Design Radical versus Modelo de Melhoria Incremental):

\section{Abordagens de Sustentável}

inter-relacionadas

\begin{tabular}{|c|c|}
\hline Modelo de Melhoria Incremental & Design Sustentável Radical \\
\hline $\begin{array}{c}\text { Contribui para melhorar a concepção do design dentro } \\
\text { do atual sistema de produção do produto. Resulta em } \\
\text { mais objetos fabricados com a utilização de mais } \\
\text { recursos e mais energia. }\end{array}$ & $\begin{array}{l}\text { Abordagem mais fundamental que começa a redefinir } \\
\text { o papel do design de produto. Desafia as normas atuais } \\
\text { de produtos produzidos em massa } \\
\text { (conceitualmente, esteticamente e filosoficamente) }\end{array}$ \\
\hline $\begin{array}{c}\text { Ex.: The Natural Step; Cradle-to-Cradle; Product Life } \\
\text { Cycle Assessment; Factor } 10\end{array}$ & $\begin{array}{c}\text { Ex.: Emotionally Durable Design; Slow Design; Enabling } \\
\text { Solutions; Designing Sustainability }\end{array}$ \\
\hline
\end{tabular}

Fig. 01 - Design Radical versus Modelo de Melhoria Incremental. Esquema distintivo entre abordagens de design sustentável na visão de Stuart Walker

Elaborado pelos autores, com base na pesquisa realizada.

\section{AGRADECIMENTOS}

Agradecemos à Fundação de Amparo à Pesquisa do Estado de São Paulo (FAPESP) sob processo n. 2014/01356-6 que nos financia a pesquisa de onde resultou este artigo. As opiniões, hipóteses e conclusões ou recomendações expressas neste material são de responsabilidade dos autores e não necessariamente refletem a visão da FAPESP.

\section{REFERÊNCIAS}

CARDOSO, Rafael. Uma introdução à história do design. (3ª ed.). São Paulo: Blucher, 2008.

CHAPMAN, Jonathan. Emotionally Durable Design. Objects, Experience, Empathy. London: Earthscan, 2005 
EHRLOFF, Michael; MARSHALL, Tim (eds.) Design Dictionary: Perspectives on Design Terminology. Birkhäuser: Basel · Boston · Berlin, 2008.

FLEMING, Rob. Design Education for a Sustainable Future. London: Eartscan, 2013

FUAD-LUKE, Alastair. Design activism: beautiful strangeness for a sustainable world. Oxon: Earthscan, 2009

GUINÉE, J.B et al. Handbook on life cycle assessment. Operational guide to the ISO standards. Dordrecht: Kluwer Academic Publishers, 2002

HUITT, W. Maslow's hierarchy of needs, Educational Psychology Interactive. Valdosta, GA: Valdosta State University, 2007 - disponível em:

http://www.edpsycinteractive.org/topics/conation/maslow.html - Acesso Agosto 2016

INAYATULLAH, Sohail. Spirituality as the Fourth Bottom Line, 2009. Disponível em: http://www.metafuture.org/Articles/spirituality_bottom_line.htm - Acesso maio 2016 MCDONOUGH, W.; BRAUNGART, M. Cradle to cradle: remaking the way we make things. North Point Press: Nova York, 2002

São Paulo: GGBrasil, 2014

Cradle to cradle: criar e reciclar ilimitadamente.

MANZINI, Ezio, e JÉGOU, Francois. Sustainable everyday - scenarios of everyday life. Edizione Ambiente, Milão, 2003a

Ambiente, Milão, 2003b.

Album - a catalogue of promising solutions. Edizione

MASLOW, A. A theory of human motivation. Psychological Review 50, 2001, p. 370-96 (original 1943) Disponível em: <http://psychclassics.yorku.ca/Maslow/motivation.htm> Acesso agosto 2016

PANTALEÃO, L. F.; PINHEIRO, O. J. Análise da Função Estética / Poética na Linguagem do Design Contemporâneo In: Anais do 8o Congresso Brasileiro de Pesquisa e Desenvolvimento em Design, São Paulo, 2008. p. 3621-5

ROBÈRT, K. H. The natural step. A história de uma Revolução Silenciosa. São Paulo: Cultrix, 2002

SCHIMIDT-BLEEK, F. Factor 10: The future of stuff. In: Sustainability, Science, Practice, \& Policy, vol. 4, issue, 1, Spring, 2008 Disponível em:

<http://sspp.proquest.com/static_content/vol4iss1/SSPP-v4.1.pdf> Acesso maio 2015

WALKER, Stuart. Designing Sustainability: Making Radical Changes in a Material World, Abingdon: Routledge, 2014

Extant objects: designing things, as they are. Int. J. Sustainable

Design, Vol. 1, No. 1, 2008

Earthscan, 2006.

Sustainable by design: explorations in theory and practice. London:

The Spirit of Design: Objects, Environment and Meaning, Earthscan, London, 2011. 
WALKER, Stuart and GIARD, Jacques (orgs). The Handbook of Design for Sustainability, London: Bloomsbury Academic, 2013 